\title{
Increased left atrial pressure in non-heart failure patients with subclinical hypothyroidism and atrial fibrillation
}

\author{
Akinori Sairaku, Yukiko Nakano, Yuko Uchimura, Takehito Tokuyama, \\ Hiroshi Kawazoe, Yoshikazu Watanabe, Hiroya Matsumura and Yasuki Kihara \\ Department of Cardiovascular Medicine, Hiroshima University Graduate School of Biomedical \\ and Health Sciences, Hiroshima, Japan
}

\begin{abstract}
Background: The impact of subclinical hypothyroidism on the cardiovascular risk is still debated. We aimed to measure the relationship between subclinical hypothyroidism and the left atrial (LA) pressure.

Methods: The LA pressures and thyroid function were measured in consecutive patients undergoing atrial fibrillation (AF) ablation, who did not have any known heart failure, structural heart disease, or overt thyroid disease.

Results: Subclinical hypothyroidism ( $4.5 \leq$ thyroid-stimulating hormone $<19.9 \mathrm{mIU} / \mathrm{L}$ ) was present in $61(13.0 \%)$ of the 471 patients included. More subclinical hypothyroidism patients than euthyroid patients had persistent or long-standing persistent AF $(55.7 \%$ vs $40.2 \% ; P=0.04)$. The mean LA pressure $(10.9 \pm 4.7$ vs $9.1 \pm 4.3 \mathrm{mmHg} ; P=0.002)$ and LA V-wave pressure $(17.4 \pm 6.5$ vs $14.3 \pm 5.9 \mathrm{mmHg} ; P<0.001)$ were, respectively, higher in the patients with subclinical hypothyroidism than in the euthyroid patients. After an adjustment for potential confounders, the LA pressures remained significantly higher in the subclinical hypothyroidism patients. A multiple logistic regression model showed that subclinical hypothyroidism was independently associated with a mean LA pressure of $>18 \mathrm{mmHg}$ (odds ratio $3.94,95 \% \mathrm{Cl} 1.28-11.2 ; P=0.02$ ).

Conclusions: Subclinical hypothyroidism may increase the LA pressure in AF patients.
\end{abstract}

\author{
Correspondence \\ should be addressed \\ to A Sairaku \\ Email \\ rjrgw059@ybb.ne.jp
}

Endocrine Connections

(2016) 5, 101-106

\section{Introduction}

Overt hypothyroidism is known to increase the cardiovascular disorders, and thus there is a consensus to treat it $(1,2,3)$, as with hyperparathyroidism (4). However, it remains controversial whether that is also true for subclinical hypothyroidism $(5,6)$, defined as a mild thyroid underactive condition in which the serum thyroidstimulating hormone (TSH) concentration is raised while the serum thyroid hormone concentrations are normal (5). On the other hand, recent large-scale cohort studies have shown that subclinical hypothyroidism with a TSH
(C) 2016 The authors Published by Bioscientifica Ltd level of $\geq 10 \mathrm{mIU} / \mathrm{L}$ was associated with an increased risk of heart failure $(7,8)$. As major symptoms of heart failure are attributed to an increased left atrial (LA) pressure (9), we hypothesized that subclinical hypothyroidism was associated with an increased LA pressure. It is well known that hyperthyroidism often causes atrial fibrillation (AF) $(1,2)$, and recently, a study (10) has provided evidence supporting the notion that hypothyroidism also elicits AF. Thus, in this study we tested this hypothesis in AF patients. http://www.endocrineconnections.org DOI: 10.1530/EC-16-0012

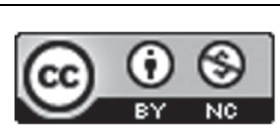

This work is licensed under a Creative Commons Attribution-NonCommercial 4.0 International License. 


\section{Materials and methods}

\section{Patients}

This study was conducted in the Hiroshima University Hospital (Hiroshima, Japan) from 2009 to 2013. Patients were eligible for inclusion if they were scheduled to undergo catheter ablation of AF for the first time. The patients were excluded if they had any history of treatment for heart failure, structural heart diseases including coronary heart disease, cardiomyopathy or moderate or severe valvular disorders, severe renal dysfunction, overt or subclinical hyperthyroidism, or overt hypothyroidism. The patients who were taking any thyroid medications were also excluded. The types of AF were defined according to the current guidelines (11). Persistent or long-standing persistent AF was collectively defined as non-paroxysmal AF. Before the ablation procedure, blood samples were obtained to assess the biochemical parameters, and an echocardiographic examination was undertaken to measure the LA and left ventricular parameters on the basis of the current guidelines (12). Written informed consent was obtained from all patients, and the study protocol was approved by the research committee of the institution.

\section{Measurement of the thyroid function}

The plasma levels of the TSH, free tri-iodothyronine $\left(\mathrm{T}_{3}\right)$, and free thyroxine $\left(\mathrm{T}_{4}\right)$ were measured using an electrochemiluminescence immunoassay (Cobas 8000; Roche Diagnostics). The reference ranges for the TSH, free $\mathrm{T}_{3}$, and free $\mathrm{T}_{4}$ were $0.005-100 \mathrm{mIU} / \mathrm{L}, 0.26-32.55 \mathrm{pg} / \mathrm{mL}$, and $0.023-7.77 \mathrm{ng} / \mathrm{dL}$, respectively. The inter-assay and intra-assay coefficients of variation were $<10 \%$ for each of the thyroid hormones. Euthyroidism was defined as a TSH level of 0.45-4.49 mIU/L, and subclinical hypothyroidism as a TSH level of 4.5-19.9 mIU/L (13).

\section{Pressure study}

Transthoracic cardioversion was applied to restore sinus rhythm in the patients with non-paroxysmal AF. After a transseptal catheterization, the pressure was measured during sinus rhythm through an 8.5-French sheath inserted into the LA with a hemodynamic monitoring system (Cardio Master, Nihon Koden, Tokyo, Japan). The LA peak A-wave pressure, LA peak V-wave pressure, and mean LA pressure were recorded (14). The central venous pressure was then measured using a 8.0-French sheath

Table 1 Clinical characteristics of patients with subclinical hypothyroidism and euthyroidism.

\begin{tabular}{|c|c|c|c|}
\hline & Euthyroidism & $\begin{array}{c}\text { Subclinical } \\
\text { hypothyroidism }\end{array}$ & $P$ value \\
\hline & $n=410$ & $n=61$ & \\
\hline Age (years) & $60.7 \pm 10.5$ & $63.9 \pm 9.9$ & 0.03 \\
\hline Male & $337(82.2 \%)$ & $46(75.4 \%)$ & 0.22 \\
\hline Diabetes & $49(12.0 \%)$ & $9(14.8 \%)$ & 0.53 \\
\hline Hypertension & $194(47.3 \%)$ & $35(57.4 \%)$ & 0.17 \\
\hline Body mass index $\left(\mathrm{kg} / \mathrm{m}^{2}\right)$ & $24.0 \pm 3.0$ & $24.0 \pm 3.2$ & 0.95 \\
\hline AF type & & & 0.04 \\
\hline Paroxysmal AF & $245(59.8 \%)$ & $27(44.3 \%)$ & \\
\hline Persistent AF & $48(11.7 \%)$ & $13(21.3 \%)$ & \\
\hline Long-standing persistent AF & $117(28.5 \%)$ & $21(34.4 \%)$ & \\
\hline Left atrial volume index $\left(\mathrm{mL} / \mathrm{m}^{2}\right)$ & $41 \pm 11$ & $47 \pm 13$ & $<0.001$ \\
\hline Left ventricle end-diastolic volume $(\mathrm{mL})$ & $103 \pm 23$ & $101 \pm 22$ & 0.65 \\
\hline Left ventricle end-systolic volume $(\mathrm{mL})$ & $39 \pm 13$ & $45 \pm 17$ & 0.1 \\
\hline Inter-ventricular septal thickness (mm) & $9.3 \pm 1.7$ & $9.1 \pm 1.2$ & 0.47 \\
\hline Left ventricular ejection fraction (\%) & $61 \pm 6$ & $58 \pm 7$ & 0.01 \\
\hline NT pro-BNP (pg/mL) & $174(63-467)$ & $242(130-709)$ & 0.008 \\
\hline eGFR $\left(\mathrm{mL} / \mathrm{min} / 1.73 \mathrm{~m}^{2}\right)$ & $71.1 \pm 15.2$ & $65.6 \pm 15.8$ & 0.009 \\
\hline Total cholesterol (mg/dL) & $213.6 \pm 34.5$ & $208.0 \pm 34.1$ & 0.25 \\
\hline Amiodarone & $48(11.7 \%)$ & $16(26.2 \%)$ & 0.002 \\
\hline Thyroid-stimulating hormone (mIU/L) & $2.1(1.41-2.9)$ & $5.99(5.16-7.61)$ & $<0.001$ \\
\hline Free tri-iodothyronine $(\mathrm{pg} / \mathrm{mL})$ & $2.92 \pm 0.43$ & $2.78 \pm 0.41$ & 0.02 \\
\hline Free thyroxine (ng/dL) & $1.28 \pm 0.19$ & $1.22 \pm 0.19$ & 0.02 \\
\hline
\end{tabular}

The values are the mean \pm S.D. or median (interquartile range). Euthyroidism was defined as a thyroid-stimulating hormone level of 0.45-4.49 $\mathrm{mIU} / \mathrm{L}$, and subclinical hypothyroidism as a level of 4.5-19.9 mIU/L. AF, atrial fibrillation; NT pro-BNP, N-terminal probrain natriuretic peptide; eGFR, estimated glomerular filtration rate.

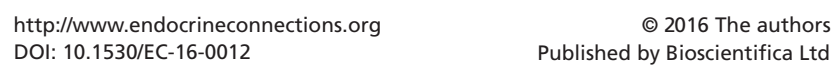


advanced into the right atrium. The arterial pressure was also recorded through a 3-French sheath placed into the femoral artery. The average pressure values of five consecutive beats were used for the analyses. Based on the Forrester classification (15), some medical interventions were taken into account when the mean LA pressure was $>18 \mathrm{mmHg}$.

\section{Endpoints}

The endpoint of this study was the LA pressure in patients with AF, who had subclinical hypothyroidism, and in those with euthyroidism.

\section{Statistical analysis}

The continuous variables were summarized as the mean \pm S.D. or medians with interquartile ranges, and categorical variables as proportions. The differences between the euthyroid patients and subclinical hypothyroid patients were determined using Pearson's $\chi^{2}$-test or Fisher's exact test for categorical variables, or Mann-Whitney $\mathrm{U}$ tests for continuous variables. The LA pressures were adjusted for potential confounders by using logistic regression models. Factors with an independent association with a mean LA pressure of $>18 \mathrm{mmHg}$ was also

Table 2 Hemodynamic parameters of patients with subclinical hypothyroidism and euthyroidism.

\begin{tabular}{|c|c|c|c|}
\hline Variables & Euthyroidism & $\begin{array}{c}\text { Subclinical } \\
\text { hypothyroidism }\end{array}$ & $P$ value \\
\hline & $n=410$ & $n=61$ & \\
\hline $\begin{array}{l}\text { Heart rate in sinus } \\
\text { rhythm (beats/ } \\
\text { minute) }\end{array}$ & $75 \pm 13$ & $74 \pm 16$ & 0.47 \\
\hline $\begin{array}{l}\text { Systolic blood } \\
\text { pressure }(\mathrm{mmHg})\end{array}$ & $141 \pm 20$ & $139 \pm 20$ & 0.43 \\
\hline $\begin{array}{l}\text { Diastolic blood } \\
\text { pressure }(\mathrm{mmHg})\end{array}$ & $75 \pm 13$ & $73 \pm 10$ & 0.27 \\
\hline $\begin{array}{l}\text { Mean central } \\
\text { venous pressure } \\
(\mathrm{mmHg})\end{array}$ & $5.1 \pm 3.6$ & $5.9 \pm 3.6$ & 0.13 \\
\hline $\begin{array}{l}\text { Left atrial peak } \\
\text { A-wave pressure } \\
\text { (mmHg) }\end{array}$ & $11.9 \pm 4.4$ & $13.2 \pm 5.2$ & 0.05 \\
\hline $\begin{array}{l}\text { Left atrial peak } \\
\text { V-wave pressure } \\
\text { (mmHg) }\end{array}$ & $14.3 \pm 5.9$ & $17.4 \pm 6.5$ & $<0.001$ \\
\hline $\begin{array}{l}\text { Mean left atrial } \\
\text { pressure }(\mathrm{mmHg})\end{array}$ & $9.1 \pm 4.3$ & $10.9 \pm 4.7$ & 0.002 \\
\hline
\end{tabular}

The values are the mean \pm S.D.

http://www.endocrineconnections.org
$\begin{array}{lr}\text { DOI: } 10.1530 / \text { EC-16-0012 } 2016 \text { The authors } \\ \text { Published by Bioscientifica Ltd }\end{array}$

determined using multiple logistic analyses. All statistical analyses were performed using JMP software version 11.0 (SAS Institute, Cary, NC, USA). A $P$ value of $<0.05$ was considered to be significant.
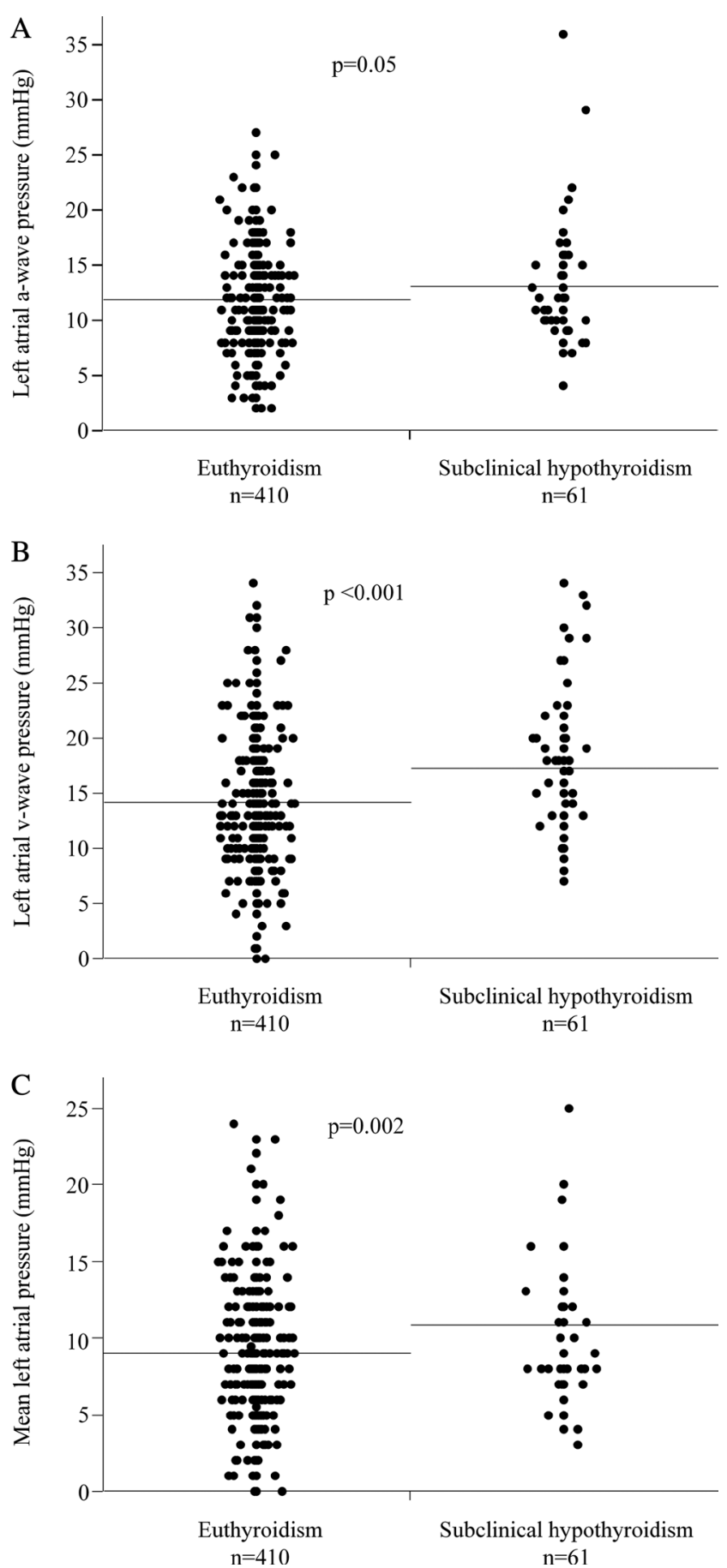

Figure 1

The left atrial A-wave pressure (A), left atrial V-wave pressure (B), and mean left atrial pressure $(C)$ in the patients with euthyroidism and patients with subclinical hypothyroidism.

This work is licensed under a Creative Commons Attribution-NonCommercial 4.0 International License. 


\section{Results}

\section{Patients}

A total of 534 patients were eligible. We found 18 patients who had been on current or previous treatment for heart failure, 24 with any structural heart disease, 3 with severe renal dysfunction, 13 with overt or subclinical hyperthyroidism, and 14 with overt hypothyroidism. Nine patients had the coexistence of two of the aforementioned pathological conditions. Therefore, we excluded a total of 63 patients, and finally studied 471 patients. The mean age of the patients was $61.2 \pm 10.4$ years, and $383(81.3 \%)$ were males. The patients with subclinical hypothyroidism were older and were more likely to have non-paroxysmal AF than the patients with euthyroidism (Table 1). The LA volume index and N-terminal probrain natriuretic peptide level were significantly greater, and the left ventricular ejection fraction and estimated glomerular filtration rate were significantly smaller in the subclinical hypothyroid patients than in the euthyroid patients. More patients with subclinical hypothyroidism were prescribed with euthyroidism than the patients with euthyroidism (Table 1).

\section{Outcomes}

The central venous pressure and arterial pressure were identical; however, the LA A-wave pressure, LA V-wave pressure, and mean LA pressure were significantly greater in the patients with subclinical hypothyroidism than in those with euthyroidism (Table 2 and Fig. 1) After an adjustment for the baseline characteristics with a significant difference between the groups, the LA pressures remained more increased in the subclinical hypothyroidism patients (Table 3). A multiple logistic regression model showed that subclinical hypothyroidism was independently associated with a mean LA pressure of $>18 \mathrm{mmHg}$ (Table 4 ).

\section{Discussion}

The major findings of this study were as follows: (i) the LA pressures and those adjusted for potential confounders were significantly higher in patients with subclinical hypothyroidism than in those with euthyroidism among the AF subjects and (ii) subclinical hypothyroidism was independently associated with a clinically significant increase in the LA pressure in the AF patients.

Hypothyroidism is known to promote myocardial fibrosis by stimulating fibroblasts $(10,16)$. Furthermore,

Table 3 Left atrial pressures adjusted for potential confounders.

\begin{tabular}{|c|c|c|c|}
\hline Variables & Euthyroidism & $\begin{array}{c}\text { Subclinical } \\
\text { hypothyroidism }\end{array}$ & $P$ value \\
\hline & $n=410$ & $n=61$ & \\
\hline $\begin{array}{l}\text { Adjusted left atrial } \\
\text { peak A wave } \\
\text { pressure }(\mathrm{mmHg})\end{array}$ & $12 \pm 0.8$ & $12.3 \pm 0.9$ & 0.03 \\
\hline $\begin{array}{l}\text { Adjusted left atrial } \\
\text { peak V wave } \\
\text { pressure }(\mathrm{mmHg})\end{array}$ & $14.5 \pm 2$ & $15.2 \pm 2.1$ & 0.01 \\
\hline $\begin{array}{l}\text { Adjusted mean left } \\
\text { atrial pressure } \\
(\mathrm{mmHg})\end{array}$ & $9.2 \pm 1.6$ & $9.8 \pm 1.6$ & 0.005 \\
\hline
\end{tabular}

The values are the mean \pm S.D. Each variable was adjusted for the age, type of $A F$, left atrium volume index, left ventricular ejection fraction, e-GFR, and amiodarone. The abbreviations are the same as in Table 1.

an experimental study in rats showed that chronic hypothyroidism leads to a loss of coronary arterioles, impaired blood flow, and maladaptive changes in the myocyte shape (17). All these unfavorable effects of overt hypothyroidism on the heart were responsible for an increase in the left ventricular end-diastolic pressure (18), leading to clinical heart failure (3). Recently, several studies have shown that subclinical hypothyroidism induces heart failure as well $(7,8,19,20)$, although it is no more than a mild thyroid underactivity. To the best of our knowledge, we for the first time assessed the relationship between subclinical hypothyroidism and the LA pressure measured by an invasive method, and found a greater LA pressure in patients with subclinical hypothyroidism. It is needless to say that the LA pressure is almost identical to the left ventricular pressure at end-diastole (21), and a significant increase in the left ventricular end-diastolic pressure is responsible for congestive heart failure (9). Therefore, it might seem that the increase in the LA pressure observed in the subclinical hypothyroidism patients increased the risk for heart failure. However, we were unable to conclude that this speculation was true, because the difference in

Table 4 Multivariate odds ratio for a mean left atrial pressure of $>18 \mathrm{mmHg}$.

\begin{tabular}{|c|c|c|}
\hline Variables & $\begin{array}{c}\text { Odds ratio ( } 95 \% \\
\text { Confidence interval) }\end{array}$ & $P$ value \\
\hline Age $>65$ years & $1(0.33-2.8)$ & 0.99 \\
\hline Non-paroxysmal AF & $2.04(0.72-6.22)$ & 0.18 \\
\hline $\begin{array}{l}\text { Subclinical } \\
\text { hypothyroidism }\end{array}$ & $3.94(1.28-11.2)$ & 0.02 \\
\hline
\end{tabular}

Non-paroxysmal AF, persistent or long-standing persistent atrial fibrillation.

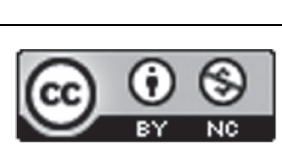


the LA pressures between the euthyroid and subclinical hypothyroid patients in our series was so small, which was hardly associated with the clinical decision-making. Nevertheless, our findings at least suggest that thyroid underactivity itself may contribute to a cardiac substrate favoring heart failure to a lesser extent in AF patients, even though it is only a milder one.

We also found that more patients with subclinical hypothyroidism had non-paroxysmal AF rather than paroxysmal AF, and had an advanced age as compared with the euthyroid patients. This probably led to some intergroup differences in the baseline characteristics (14). However, after an adjustment for the potential confounders by using logistic regression models, subclinical hypothyroidism remained to be associated with an increased LA pressure. There are several known factors responsible for an increased LA pressure, such as hypertension, valvular insufficiencies, myocardial ischemia, and cardiomyopathies (22). The findings mentioned above thus suggest that not only overt hypothyroidism, but also subclinical hypothyroidism may be one of the factors.

It is controversial whether or not hypothyroidism predisposes to the development of AF (23). Zhang and coworkers (10), however, recently stated in their work that both the atrial fibrosis and ion channel remodeling caused by hypothyroidism provide an arrhythmogenic substrate favoring AF. The authors also mentioned that heart failure resulting from hypothyroidism contributes to the development of AF. These facts may explain the higher prevalence of non-paroxysmal AF, a more advanced form of $\mathrm{AF}$, in patients with subclinical hypothyroidism. It is well known that amiodarone sometimes causes a decline in the thyroid function (24). In our series, amiodarone was more frequently prescribed for patients with non-paroxysmal AF in order to suppress an early recurrence of AF occurring after ablation. Thus, this fact also possibly contributed to the frequent coexistence of non-paroxysmal AF and subclinical hypothyroidism in this study.

\section{Clinical implications}

The findings of this study may give important insights into the controversy over the relationship between subclinical hypothyroidism and heart failure, because we for the first time shed light on its cardiac physiological aspect. Large-scale studies showed that subclinical hypothyroidism with a TSH level of $\geq 10 \mathrm{mIU} / \mathrm{L}$ was associated with an increased risk of heart failure $(7,8)$. However, there is still no consensus on the need for medical intervention for high-risk patients $(5,6)$. Therefore, whether thyroid hormone replacement therapy for patients with subclinical hypothyroidism and an elevated LA pressure prevents heart failure is a future challenge.

\section{Limitations}

We studied only a selected population of patients with AF. Therefore, it is uncertain whether our findings are also true for the general population. Secondly, this study was no more than a cross-sectional study. Finally, this study was a small-scale, single-center study.

\section{Declaration of interest}

The authors declare that there is no conflict of interest that could be perceived as prejudicing the impartiality of the research reported.

\section{Funding}

This work did not receive any specific grant from any funding agency in the public, commercial, or not-for-profit sector.

\section{References}

1 Klein I \& Ojamaa K. Thyroid hormone and the cardiovascular system. New England Journal of Medicine 2001344 501-509. (doi:10.1056/ NEJM200102153440707)

2 Klein I \& Danzi S. Thyroid disease and the heart. Circulation 2007116 1725-1735. (doi:10.1161/CIRCULATIONAHA.106.678326)

3 Gerdes AM \& Iervasi G. Thyroid replacement therapy and heart failure. Circulation 2010122 385-393. (doi:10.1161/ CIRCULATIONAHA.109.917922)

4 van Ballegooijen AJ, Reinders I, Visser M \& Brouwer IA. Parathyroid hormone and cardiovascular disease events: a systematic review and meta-analysis of prospective studies. American Heart Journal 2013165 655-664. (doi:10.1016/j.ahj.2013.02.014)

5 Cooper DS \& Biondi B. Subclinical thyroid disease. Lancet 2012379 1142-1154. (doi:10.1016/S0140-6736(11)60276-6)

6 Klein I. Subclinical hypothyroidism - just a high serum thyrotropin (TSH) concentration or something else? Journal of Clinical Endocrinology and Metabolism 201398 508-510. (doi:10.1210/jc.2012-4088)

7 Rodondi N, Bauer DC, Cappola AR, Cornuz J, Robbins J, Fried LP, Ladenson PW, Vittinghoff E, Gottdiener JS \& Newman AB. Subclinical thyroid dysfunction, cardiac function, and the risk of heart failure. The Cardiovascular Health study. Journal of the American College of Cardiology 200852 1152-1159. (doi:10.1016/j.jacc.2008.07.009)

8 Gencer B, Collet TH, Virgini V, Bauer DC, Gussekloo J, Cappola AR, Nanchen D, den Elzen WP, Balmer P, Luben RN et al. Thyroid studies collaboration. Subclinical thyroid dysfunction and the risk of heart failure events: an individual participant data analysis from 6 prospective cohorts. Circulation 2012126 1040-1049. (doi:10.1161/ CIRCULATIONAHA.112.096024)

9 Poole-Wilson PA \& Buller NP. Causes of symptoms in chronic congestive heart failure and implications for treatment. American Journal of Cardiology 198862 31A-34A. (doi:10.1161/ CIRCHEARTFAILURE.114.002091)

10 Zhang Y, Dedkov EI, Teplitsky D, Weltman NY, Pol CJ, Rajagopalan V, Lee B \& Gerdes AM. Both hypothyroidism and hyperthyroidism increase atrial fibrillation inducibility in rats.

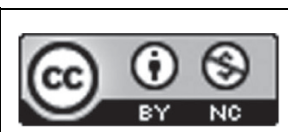


Circulation: Arrhythmia and Electrophysiology 20136 952-959. (doi:10.1161/CIRCEP.113.000502)

11 Calkins H, Kuck KH, Cappato R, Brugada J, Camm AJ, Chen SA, Crijns HJ, Damiano RJ Jr, Davies DW, DiMarco J, et al. 2012 HRS/EHRA/ECAS expert consensus statement on catheter and surgical ablation of atrial fibrillation: recommendations for patient selection, procedural techniques, patient management and follow-up, definitions, endpoints, and research trial design: a report of the Heart Rhythm Society (HRS) Task Force on Catheter and Surgical Ablation of Atrial Fibrillation. Developed in partnership with the European Heart Rhythm Association (EHRA), a registered branch of the European Society of Cardiology (ESC) and the European Cardiac Arrhythmia Society (ECAS); and in collaboration with the American College of Cardiology (ACC), American Heart Association (AHA), the Asia Pacific Heart Rhythm Society (APHRS), and the Society of Thoracic Surgeons (STS). Endorsed by the governing bodies of the American College of Cardiology Foundation, the American Heart Association, the European Cardiac Arrhythmia Society, the European Heart Rhythm Association, the Society of Thoracic Surgeons, the Asia Pacific Heart Rhythm Society, and the Heart Rhythm Society. Heart Rhythm 20129 632-696. (doi:10.1016/j.hrthm.2011.12.016)

12 Lang RM, Bierig M, Devereux RB, Flachskampf FA, Foster E, Pellikka PA, Picard MH, Roman MJ, Seward J, Shanewise JS, et al. Recommendations for chamber quantification: a report from the American Society of Echocardiography's Guidelines and Standards Committee and the Chamber Quantification Writing Group, developed in conjunction with the European Association of Echocardiography, a branch of the European Society of Cardiology. Journal of the American Society of Echocardiography 200518 1440-1463. (doi:10.1016/j.echo.2005.10.005)

13 Cappola AR, Fried LP, Arnold AM, Danese MD, Kuller LH, Burke GL, Tracy RP \& Ladenson PW. Thyroid status, cardiovascular risk, and mortality in older adults. JAMA 2006295 1033-1041. (doi:10.1001/ jama.295.9.1033)

14 Sairaku A, Nakano Y, Oda N, Uchimura Y, Tokuyama T, Kawazoe H, Fujiwara M, Watanabe Y, Matsumura H \& Kihara Y. Incomplete cure of tachycardia-induced cardiomyopathy secondary to rapid atrial fibrillation by heart rate control without sinus conversion. Journal of Cardiovascular Electrophysiology 201425 1037-1043. (doi:10.1111/ jce.12445)

15 Forrester JS, Diamond GA \& Swan HJ. Correlative classification of clinical and hemodynamic function after acute myocardial infarction.

American Journal of Cardiology 197739 137-145. (doi:10.1016/S00029149(77)80182-3)

16 Chen WJ, Lin KH \& Lee YS. Molecular characterization of myocardial fibrosis during hypothyroidism: evidence for negative regulation of the pro-alpha1(I) collagen gene expression by thyroid hormone receptor. Molecular and Cellular Endocrinology 2000162 45-55. (doi:10.1016/S0303-7207(00)00203-3)

17 Tang YD, Kuzman JA, Said S, Anderson BE, Wang X, Gerdes AM. Low thyroid function leads to cardiac atrophy with chamber dilatation, impaired myocardial blood flow, loss of arterioles, and severe systolic dysfunction. Circulation 2005112 3122-3130. (doi:10.1161/ CIRCULATIONAHA.105.572883)

18 Lavine SJ, Prcevski P, Held AC \& Johnson V. Experimental model of chronic global left ventricular dysfunction secondary to left coronary microembolization. Journal of the American College of Cardiology 1991 18 1794-1803. (doi:10.1016/0735-1097(91)90523-C)

19 Rodondi N, Newman AB, Vittinghoff E, de Rekeneire N, Satterfield S, Harris TB \& Bauer DC. Subclinical hypothyroidism and the risk of heart failure, other cardiovascular events, and death. Archives of Internal Medicine 2005165 2460-2466. (doi:10.1001/ archinte.165.21.2460)

20 Ripoli A, Pingitore A, Favilli B, Bottoni A, Turchi S, Osman NF, De Marchi D, Lombardi M, L'Abbate A \& Iervasi G. Does subclinical hypothyroidism affect cardiac pump performance? Evidence from a magnetic resonance imaging study. Journal of the American College of Cardiology 200545 439-445. (doi:10.1016/j. jacc.2004.10.044)

21 Ishida Y, Meisner JS, Tsujioka K, Gallo JI, Yoran C, Frater RW $\&$ Yellin EL. Left ventricular filling dynamics: influence of left ventricular relaxation and left atrial pressure. Circulation $1986 \mathbf{7 4}$ 187-196. (doi:10.1161/01.CIR.74.1.187)

22 Pagel PS, Kehl F, Gare M, Hettrick DA, Kersten JR \& Warltier DC. Mechanical function of the left atrium: new insights based on analysis of pressure-volume relations and Doppler echocardiography. Anesthesiology 200398 975-994. (doi:10.1097/00000542-20030400000027)

23 Kim EJ, Lyass A, Wang N, Massaro JM, Fox CS, Benjamin EJ \& Magnani JW. Relation of hypothyroidism and incident atrial fibrillation (from the Framingham Heart Study). American Heart Journal 2014167 123-126. (doi:10.1016/j.ahj.2013.10.012)

24 Basaria S \& Cooper DS. Amiodarone and the thyroid. American Journal of Medicine 2005118 706-714. (doi:10.1016/j.amjmed.2004.11.028)

Received in final form 4 February 2016

Accepted 19 February 2016 http://www.endocrineconnections.org DOI: 10.1530/EC-16-0012
() 2016 The authors Published by Bioscientifica Ltd

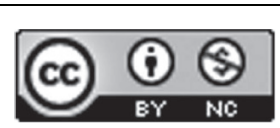

This work is licensed under a Creative Commons Attribution-NonCommercial 4.0 International License. 